\title{
EL ARTE, UN CAMINO PARA SANAR
}

\section{Art, a way for healing}

\author{
Milagros Meza Alvarez*
}

\begin{abstract}
Resumen
Este artículo pretende ser un primer acercamiento hacia las Terapias de Arte, ya que si bien tiene un desarrollo de varios años en otras partes del continente, es relativamente nuevo en nuestro país como disciplina. Se pretende dar un recorrido histórico, una definición, algunos fundamentos teóricos que sustentan esta práctica, hasta presentar nuestra propuesta en la formación de profesionales a través del Diplomado que se viene impartiendo ya hace algunos años en esta Universidad.
\end{abstract}

Palabras clave: Arte terapia.

\begin{abstract}
This article intends to be an approach to Art Therapies since although they have been developed for many years in other areas of the continent; they are relatively new in our country, as a discipline. We pretend to provide with a historical review, a definition and some theoretical basics sustaining this practice. Finally, we present our proposal in the formation of professionals through the Diploma Course this university has offered since some years ago.
\end{abstract}

Key words: Art Therapy.

\footnotetext{
* Directora del Diplomado de Terapias de Arte, Universidad Femenina del Sagrado Corazón. Psicoterapeuta a través del arte.
} 
Solo tengo que regresar a mi infancia, en esa sierra maravillosa llena de color y de formas, con el olor a tierra mojada por esa lluvia infinita. Penetrando mis pies en ese río que acaricia y latiga. Es ahí donde empiezo a descubrir las enormes posibilidades del juego y del arte.

\section{ORÍGENES DE LA PROPUESTA}

$\mathrm{El}$ arte surge como una necesidad del ser humano de expresarse y dejar una huella, ha sido siempre un instrumento de registro y de conexión. Su riqueza reside en sus múltiples posibilidades; no solo en relación a los diferentes lenguajes que ofrece, sino a la posibilidad de liberación y de comunicación.

Es en esta época, cada vez más individualista, con mucha tecnología, donde se ha dejado de lado la experimentación a través de los sentidos, el contacto físico y el juego, donde retornamos al arte como una alternativa de salud. Se empieza a elaborar una nueva metodología de abordaje terapéutico, donde se utiliza el arte como canal de comunicación, expresión, creación e integración.

Los orígenes de esta propuesta podrían ubicarse alrededor de la segunda guerra mundial, donde se utiliza el dibujo y la pintura como medio de expresión, así algunos pacientes descubren que pueden liberarse de sus tensiones, miedos, angustias, culpas a partir de sus experiencias creativas. Es Adrian Hill artista plástico que pasaba su convalecencia en un sanatorio recuperándose de una tuberculosis, quien se da cuenta que al explorar sus experiencias mediante el arte, el proceso creativo lo ayudaba a recuperarse emocionalmente, encuentra en el arte un soporte y un alivio, logra que algunos de sus compañeros lo practiquen como medio catártico; y luego de la guerra sigue en la práctica siendo considerado por algunos como el primer arte terapeuta remunerado. En 1943 publica su primera obra "Art as an aid to illness; an experiment in occupational Therapy"

Ya en distintas partes del mundo se empieza a reconocer en el arte las enormes posibilidades tanto en el diagnóstico como en los tratamientos psicológicos. Se crean las pruebas proyectivas a través del dibujo, se va introduciendo poco a poco en las terapias sobre todo con los niños. Sin embargo el arte era aún una herramienta más, y los valores artísticos eran todavía secundarios. Simultáneamente aparecen nuevas formas de enseñanza donde se refuerza el uso de la creatividad en el desarrollo de niños y adolescentes. Estos enfoques fueron influenciados por profesores de educación artística entre ellos Herbert Read y Victor Lowenfeld, quienes aportaron mucho en el tema de desarrollo y arte.

Las Terapias de arte, empiezan a formalizarse cuando un grupo de personas de diferente procedencia (sobre todo artistas, psicólogos y educadores) descubren la forma de poner el arte al servicio de los demás.

Muchos consideran a Margaret Naumburg y Edith Kramer como las pioneras más reconocidas en esta nueva profesión, quienes hacen sus investigaciones en Norteamérica.

Margaret Naumburg (1890-1983). Proviene desde la pedagogía, crea en 1914 la escuela Walden en Nueva York, donde puso en práctica su idea de que la expresión creativa espontánea, acercaba al niño al mismo aprendizaje que el método intelectual tradicional, alienta hacia la necesidad urgente de hacer cambios a nivel educativo.

Luego tiene un trabajo bastante extenso desde la psicoterapia con pacientes en sanatorios psiquiátricos

Fue la primera que utilizó el proceso artístico de una manera sistemática. Para ella el arte es un lenguaje simbólico, le interesa develar su significado, utiliza la interpretación verbal, los procesos transferenciales, sin darle mucho énfasis a la calidad artística, es importante seguir el ritmo del paciente.

Es Moccio, F (1994) quien sintetiza el aporte de Naumburg en tres grandes temas en relación a la pintura como psicoterapia: "Primero los pensamientos y sentimientos del hombre derivados del inconsciente, se expresan en imágenes más bien que en palabras; segundo que todo individuo posee una capacidad latente para proyectar sus conflictos interiores en forma visual; tercero, las producciones inconscientes escapan más fácilmente que las expresiones verbales a la propia censura mental." (p. 16) 
Edith Kramer, (Viena 1916) pone énfasis en las posibilidades curativas que se dan al activar los procesos psíquicos cuando el paciente crea, considera al arte útil para transformar fantasías inconscientes, un camino hacia la sublimación, una forma de integrar sentimientos conflictivos de una manera estética, permite trabajar con emociones regresivas por su capacidad de evocación casi inmediata. Kramer comenzó a trabajar como arte terapeuta en una comunidad para niños con enfermedades mentales en Nueva York. De esa experiencia escribe "Terapia a través del arte en una comunidad infantil" (1958).

Ambas terapeutas creen en las grandes posibilidades del arte para abordar más fácilmente el inconsciente.

Siguiendo una línea cronológica, algunas de las fechas importantes son:

- 1950: Marion Millnes publicó "Oh no being able to paint" donde aparecen los primeros programas de estudio de arte terapia.

- 1959: nace la SIPE (Societé Internationales de Psychopathologic del Expression)

- 1961: aparece el primer número de la revista American Jornal of Art Therapy.

- 1964: se funda la Asociación Británica de Arte Terapeutas, por un grupo de artistas y terapeutas.

- 1969: se funda la AATA (American Art Therapy Association) en estados Unidos

- 1973: se inaugura en Río de Janeiro el Museo de Imágenes del Inconsciente

A medida que va surgiendo el interés en el resto del mundo, nuestro país no es ajeno a este nuevo movimiento.

En el año 1996 convergen en un equipo de trabajo José Bárcenas (psicólogo y músico), Luz María Garrido Leca (artista plástica), Matilde Hall (drama terapeuta), Mariana Santisteban (terapeuta de arte) quienes forman la Asociación de Terapias de Arte e inician su labor con la puesta en exhibición de una importante selección de trabajos plásticos elaborados por pacientes del Hospital Psiquiátrico Víctor Larco Herrera.
Luego nos vamos incorporando diferentes profesionales, formamos el EQUIPO de Terapias de Arte y es a partir del 2001 donde iniciamos el Proyecto de Diplomado de Terapias de Arte, se inició en la Universidad Mayor de San Marcos para luego incorporarlo en la Universidad Femenina del Sagrado Corazón desde el 2004 hasta la actualidad. Y es el único en el país respaldada por una Universidad Peruana.

Asimismo surge TAE Perú Terapia de Artes Expresivas, quienes trabajan con el método intermodal, es decir incorporan las diferentes modalidades del arte. Promoviendo el uso de las artes en lo terapéutico educativo y comunitario.

Es actualmente en Estados Unidos donde las terapias de arte alcanzan su mayor desarrollo. Asimismo en Gran Bretaña y Francia donde se le considera de gran apoyo en el diagnóstico e investigación de la salud mental.

Por otro lado, la organización de Congresos internacionales está permitiendo el intercambio de propuestas e investigaciones. Logrando mayor fuerza y validación en el campo de la salud mental. El próximo año, en octubre está programado el siguiente Congreso Internacional en Brasil.

\section{¿Cómo definimos Arte Terapia?}

Para la Asociación Argentina de Arte Terapia:

"Es una profesión de servicios humanos que utiliza materiales de arte (plástico), imágenes, el proceso creativo y las respuestas del paciente/cliente hacia los productos creados, como reflejos de desarrollo individual, habilidades, personalidad, intereses, preocupaciones y conflictos. La práctica de Terapias por el arte se basa en el conocimiento de la teoría de desarrollo humano y las teorías psicológicas que han sido implementadas en un amplio espectro de modelos de evaluación y tratamiento, incluyendo modelos educativos, psicodinámicos, cognitivos y transpersonales, entre otros, para aliviar conflictos emocionales, promover el conocimiento y la conciencia de uno mismo, desarrollar aptitudes de sociabilización, manejar comportamientos inadecuados, solucionar 
problemas, reducir la ansiedad, ayudar a clarificar la realidad e incrementar la autoestima".

Es importante remarcar que esta es una disciplina, que va adquiriendo identidad propia. Si bien nace muy ligada a la psicología, no debemos entenderla como una extensión; es una nueva entidad, que aunque está conformada por ambos universos, es mucho más que la suma de ellos.

\section{Para EL EQUIPO de Terapias de Arte:}

"La Terapia de arte es una profesión de servicio humano que utiliza los materiales de arte (el sonido, la plástica, el drama y el movimiento), el proceso creativo y las respuestas del paciente hacia los productos creados, como reflejos de desarrollo individual, habilidades, personalidad, intereses, preocupaciones y conflicto.

Son un tratamiento efectivo para aquellos con problemas de desarrollo, de aprendizaje, de socialización, problemas psicológicos o médicos.

Las Terapias de Arte pueden ser útiles no solamente a personas que sufren dolencias severas psicológicas o médicas sino también a personas con un adecuado funcionamiento a nivel personal y laboral".

Como ya lo habíamos mencionado, dentro de la psicología, el arte se viene usando como una herramienta auxiliar desde hace mucho tiempo. Se usa a nivel diagnóstico con pruebas proyectivas como el Test de la figura humana, el HTP, Test de la familia, entre otros y también en el plano terapéutico, como una forma de relacionarse entre terapeuta y paciente. Sin embargo no se había usado el arte como posibilidad de expresión y comunicación, dándole importancia al proceso creativo y consiguiendo a través de la experiencia con los diferentes lenguajes artísticos una herramienta valiosa de elaboración y transformación de la persona.

Se han ido dando de manera independiente varias formas de trabajar con los lenguajes del arte, encontramos así a la musicoterapia, el psicodrama, la biodanza. Que se fueron trabajando de forma independiente consiguiendo su propio espacio y fueron planteando también sus propias propuestas.
Si bien la mayoría de investigaciones hechas en el campo de las Terapias de Arte corresponden a la plástica, hay cada vez más experiencias con la danza, el teatro, los títeres la fotografía, la música. el video y la literatura. Lo que nos da enormes posibilidades para trabajar en un nivel preventivo, terapéutico a nivel individual y grupal.

\section{¿Cuáles son las ventajas que nos da el arte?}

Casi nos hemos acostumbrado a pensar que la única manera de comunicarnos es de forma verbal, sin embargo estamos todo el tiempo relacionándonos a través de nuestros gestos, nuestras posturas, nuestras miradas, nuestros tonos de voz. Y el arte responde precisamente a este otro tipo de lenguaje, el no verbal, ayuda entonces a encontrar otras formas de comunicación con uno mismo y con los demás. Nos da la posibilidad de llegar a lo profundo casi sin darnos cuenta, por un camino diferente (no convencional). Conectarnos con una parte nuestra que también quiere decirnos algo, hacer consciente lo inconsciente, vencer fácilmente las resistencias.

Por otro lado, si partimos del hecho de que todas las personas tenemos posibilidades de expresarnos a través de los medios artísticos, podemos abarcar todas las poblaciones posibles. Siguiendo a Naumburg "La técnica del arte terapia, se basa en que todos los individuos, estén o no entrenados artísticamente, poseen una capacidad latente para proyectar sus conflictos internos bajo formas visuales y que aquellos originariamente bloqueados en su expresión verbal, comienzan a verbalizar con el fin de explicar sus producciones artísticas”. Moreno (2007), p.19.

Es también en la posibilidad de crear donde reside el valor terapéutico, ya que está en la esencia del individuo el ser creativo. El individuo descubre ser persona, cuando tiene un vivir creador.

Específicamente en la plástica, nos da la posibilidad de regresar al objeto creativo para darle un nuevo significado o la posibilidad de trazar un nuevo rumbo. Pudiendo hacer nuevas conexiones, reparar (en el sentido que Melanie Klein plantea), transformar. Se establecen las condiciones necesarias para desarrollar el potencial creativo y a partir del mismo potenciar el lado 
saludable en cada ser humano, se fortalece la autoestima.

El entrar a nuestro inconsciente por medio del arte nos remite a lo lúdico y el abordaje resulta menos invasivo.

No importa lo estético, rompemos prejuicios respecto a la práctica del arte, no existen calificativos, todo lo que salga dentro del proceso es observado desde una mirada de testigo, de respeto hacia el otro. Permitiendo que se fluya libremente, eliminando barreras.

\section{En cuanto a la intervención terapéutica}

Para quienes venimos desde el psicoanálisis, el aporte de Winnicott es fundamental sobre todo en su propuesta teórica que desarrolla sobre el espacio transicional, el vínculo que se establece en el espacio potencial y el juego del niño como primer acto creativo del ser humano.

Solo en el juego pueden el niño y el adulto crear y usar toda la personalidad y el individuo descubre su persona solo cuando se muestra creador.

La creatividad para Winnicott es universal y está al lado de la salud, la adaptación masiva y el acatamiento, es atribuida a la enfermedad.

La realidad es un intermedio de experiencia entre la realidad exterior e interior. Es aquí donde ubica los fenómenos transicionales, que poco a poco darán paso al juego y a la actividad creativa.

Es en el juego donde el niño va ensayando roles, se comunica, reproduce vivencias, donde deposita su realidad y su fantasía. Así el arte y el juego pasan a ser una representación simbólica.

En términos freudianos la sublimación es la desviación hacia fines socialmente aceptados y es en este sentido que el arte ocupa un lugar importante, una nueva realidad entre los principios de realidad y del placer. El mismo que Fiorini menciona como proceso terciario.

Se incorpora el proceso artístico como lo más importante, no importa lo estético, lo fundamental es el recorrido que hace el paciente y lo que ocurre en dicho recorrido.

En cuanto al rol del arte terapeuta Sara Paín 2006 nos dice "que una vez que han sido dadas las consignas de la actividad, es seguir el comportamiento del paciente, ser testigo de su aventura, ayudarlo a salvar los obstáculos que pueda encontrar considerándolos al mismo tiempo desde puntos de vista subjetivos y objetivos. Para ello es necesario tener normas por una parte para observar a los sujetos mientras realizan una actividad creativa y por otro para decidir sobre la oportunidad y el contenido de las intervenciones. El arte terapeuta es una mirada, una escucha, una resonancia afectiva" (p. 28)

El trabajo terapéutico se basa básicamente en el vínculo paciente - objeto artístico - terapeuta, es a partir del mismo que se empieza a reconstruir la historia del paciente. Asimismo se trabaja en base a la transferencia, contratransferencia y el análisis de las resistencias.

A diferencia de una terapéutica tradicional donde la mayor parte del tiempo se le escucha al paciente; en arte terapia, se le pone a ejecutar una tarea y somos entonces observadores de cómo asimila la consigna, cuál es el tiempo que se toma para realizarla, si busca del otro, si se repliega, como se contacta con el material, como es su corporeidad, cuanto necesita o no de la aprobación del terapeuta.

Al final de la sesión al paciente tendrá una obra que hable de él, donde ha depositado contenido inconsciente. Como terapeutas, nos interesa saber cuál es el significado que tiene para el paciente, como se conecta con su obra, dónde la deposita. Particularmente pienso que algunas veces resulta siendo muy beneficioso un cierre verbal, no necesariamente porque sea lo que resulte siendo una síntesis real de lo que le sucede, sino que precisamente en ese intento por mostrarse frente al otro donde manifiesta claramente sus resistencias y la forma como se comunica y se vincula con el otro y consigo mismo.

Uno de los aspectos más importantes del trabajo terapéutico en grupo, es la posibilidad de observar en los participantes su capacidad para escuchar y aprove- 
char de la experiencia del otro. Es a partir de esto precisamente, que podemos aliviarnos de ciertos padecimientos, algunas veces porque nos confrontamos con situaciones similares que son resueltas de manera más proactiva y por lo tanto resultan siendo menos dolorosas. Y otras porque al escuchar padecimientos mucho más complicados en el otro minimizamos los nuestros.

Otro aspecto tan importante como todo lo anteriormente descrito es lo que tiene que ver con la contratransferencia.

"Es cierto que las emociones más profundas que puede sentir el arte terapeuta provienen de la observación de la producción del sujeto: de la calidad emocional del mensaje traducido en la armonía o en la agresividad de las formas, por la exactitud o la desviación de las proporciones, la calidad de los trazos, el tema abordado, los colores y los contrastes utilizados, los ejes de diferenciación elegidos. Pero también es importante para él captar el impacto afectivo que las intervenciones de cada participante producen sobre el grupo y las relaciones de cada uno frente a las imágenes de sí que dicho grupo le devuelve". Pain, S. (2006) p. 33.

Como terapeutas debemos estar muy atentos de lo que nos provocan los pacientes, generalmente reviven en el "aquí y ahora" situaciones cotidianas, buscando justamente ese tipo de respuesta a que están acostumbrados. Es nuestra labor entonces darle un nuevo significado, lo que hará que cambie dicha conducta inadecuada y se relacione de una manera diferente.

\section{Algunas otras consideraciones importantes}

Para un trabajo de este tipo es importante también tener en cuenta el setting y los materiales. El espacio físico tiene ciertos requerimientos, los participantes necesitan de un lugar que los acoja, con ciertas características estables, como que sea amplio, iluminado, donde no haya muchas interferencias (ruidos, paso de personas, etc.) con piso lavable, lavatorio cerca; se necesita que los muebles puedan ser fácilmente movibles y un equipo de sonido, con un amplio repertorio de música de diferentes géneros y de diferentes partes del mundo. Es importante tener un espacio donde guardar los materiales y dejar los trabajos. Sobre todo porque las creaciones de los pacientes son extensiones de sí mismos, por lo tanto necesitan de cuidado.

Los materiales tienen que ser bastante accesibles, que no causen grandes frustraciones al pretender usarlos. Muchas veces el terapeuta también cumple un rol de educador cuando tiene que enseñar al paciente a usar un material determinado.

Si bien en relación al tiempo de la terapia y la frecuencia de la misma no se puede dar una aproximación exacta, es importante pensar en una duración de un año en promedio, con una frecuencia de una vez por semana como mínimo.

En cuanto a la duración de cada sesión consideramos una hora si se trabaja con niños y una hora y media o dos si lo hacemos con adolescentes y adultos.

Por otro lado, es importante también tomar en cuenta la constitución de los grupos. Por ejemplo si se trabaja con niños hay que considerar que las edades no pueden ser muy variadas ni distantes. Además es necesario también tomar en cuenta las problemáticas y los diagnósticos de los miembros del grupo. No se recomienda poner en un grupo a todos con características similares.

Los enfoques en Terapias de arte (dirigido en este caso a la plástica), como los plantea Moreno, N. (2007), podrían ser resumirlos en tres básicamente:

El primero es un enfoque directivo, el arte terapeuta estructura la sesión de trabajo, determinando actividades o temas a desarrollar, materiales o técnicas con las que el paciente pueda crear.

El segundo es no directivo. El Arte terapeuta no se involucra en el accionar del paciente, dejándolo libre de elegir materiales, técnica y el o los temas con los que desarrolla su proceso artístico.

En el tercero, se entregan lineamientos básicos, los que deben ser completados por el paciente. Las instrucciones son mínimas para que el paciente tenga la opción de completar (p.22). 
Acerca de la formación de los arte terapeutas en nuestro medio

Quienes empezamos en esta labor lo hacemos de una manera autodidacta, motivados en principio por el deseo de integrar el arte y la psicología. Es en esta búsqueda que vamos experimentando con diferentes lenguajes y encontrándole un sentido cuando de aliviar se trata. Es con la experiencia tanto en la práctica terapéutica como en lo académico donde se empieza a consolidar y entender que esta disciplina necesita de una identidad propia y tiene enormes posibilidades.

Luego van surgiendo otras personas con la misma motivación y ya hay un camino avanzado, el cual tiene que aprovecharse. Es así como se van dictando diferentes cursos y talleres, y es cada vez más la demanda y la búsqueda por integrarlo más formalmente.

Es en este momento donde nos decidimos por hacer una propuesta de Diplomado, el cual ya viene dándose de manera continua durante seis años.

Nuestra propuesta, está diseñada dentro de un aprendizaje a través de la experiencia ya que estamos convencidos que es la mejor forma de aprender. Solamente cuando alguien llegue a conocerse podrá ayudar a otro a aceptares a si mismo. Como lo mencionaba Maslow, primero hay que descubrir y después ayudar.

Durante ocho meses los alumnos experimentan con diferentes lenguajes del arte y son ellos mismos el objeto de estudio. Además el trabajo en grupo les permite observar los procesos de los otros así como ser Testigos de Honor de los mismos.

Se sustenta en cuatro ejes de trabajo fundamentales:

\section{- El Yo}

Se hace un recorrido por el interior de cada participante, siguiendo una línea de desarrollo. Buscando conectarse con el pasado como una forma de entenderse a partir de sus primeros vínculos, reparar situaciones difíciles, cerrar puertas que no están permitiendo avanzar.

Es el momento más vulnerable ya que el grupo recién se conoce, comparte experiencias no siempre agradables y empieza a tender las redes de lo que será el sustento de toda la travesía.

También es bueno aclarar que antes de seguir el proceso, se les recomienda un acompañamiento terapéutico a los participantes y una práctica en algún lenguaje artístico.

\section{- Yo y los otros}

Luego pasamos a relacionarnos con los otros, primero desde una nueva forma de vincularnos y como testigos de los procesos.

Como en todo grupo, se va explorando roles, el emergente, vínculos, resistencias, riesgos, capacidad de empatía, entre otras cosas.

\section{- La técnica}

Hacemos también un recorrido por los diferentes lenguajes artísticos, como una forma de experimentar y reconocer en nosotros mismos y en el grupo, las diferentes sensaciones provocadas por el intercambio con las técnicas y los materiales.

Planteamos juego de roles y trabajamos sobre situaciones ficticias de intervención.

\section{- El terapeuta frente al paciente/cliente}

Luego de los procesos personales, se busca introducir a los participantes en una práctica real. Que los confronta primero con un grupo de trabajo, que necesita organizarse, elaborar un proyecto y sobre todo estar muy alertas a los cambios que se tengan que ir dando en pleno proceso.

Luego trabajan en diferentes poblaciones, Clínica Psiquiátrica, Residencia de ancianos, Hogar de madres adolescentes, grupos de profesores de un colegio, grupo de alumnos con alguna necesidad específica, pacientes terminales, entre otros.

Se pretende dar un cierre a la experiencia con un trabajo concreto, práctico. Que le permite al participante pasar de su mundo al de otros y encontrar de manera inmediata una sistematización del proceso.

Lo que resulta gratificante para quienes nos iniciamos en esta aventura, es reconocer que el interés es 
cada vez mayor por esta disciplina y además que muchas de las personas que pasaron por esta formación están ya trabajando e incorporando las terapias de arte desde su práctica laboral. Esto permitirá el reconocimiento de este abordaje terapéutico en nuestro medio y el incremento de investigaciones, enriqueciéndonos todos.

Para concluir podemos decir entonces que el arte es una maravillosa forma de curar, y que las terapias de arte resultan un medio práctico y fascinante de conectarnos con nuestro mundo interno y con el otro, en una travesía donde nos está permitido crear y avanzar desde nuestras partes saludables. Además por ser el arte parte de nuestra vida desde siempre, el primer paso ya está dado, solo falta hacer las conexiones para poder integrarnos

\section{REFERENCIAS}

Allen, P. (1997). Arte Terapia. Guía de autodescubrimiento a través del arte y la creatividad. Madrid: Gaia.

Asociación Argentina de Arte Terapia (2010). Arteterapia. Disponible en internet: http// www.asoarteterapia.org.ar
Dalley, T. (1987). El arte como terapia. Barcelona: Hider.

De los Rios Moller, C. (2008). Clínica del arte Introducción a la aplicación del arte en psicoterapia. Viña del Mar: Sociedad Atenea

Kramer, E. (1982). Terapia a través del arte en una comunidad infantil. Buenos Aires: Kapelusz.

Equipo de Terapias de Arte. Disponible en internet: http//www.equipoterapiasdearte.com/

Lorenfeld, V. y Brittain, W. (1982). Desarrollo de la capacidad creadora. Buenos Aires: Kapelusz.

Moccio, F. (1994). El taller de terapias expresivas. México: Paidós.

Pain, S. y Jarreau, G. (1995). Una psicoterapia por el arte. Teoría y técnica. Buenos Aires: Nueva Visión.

Winnicott, D. (1999). Realidad y juego. Barcelona: Gedisa.

Moreno Araya, N. (2007). Arte terapia y adolescentes: Promoviendo la expresión emocional de los conflictos con la autoridad. Tesis Universidad de Chile Facultad dearte Escuela de Postgrado. Santiago. Disponible en internet: //www.ipadej.org/virtual/ $\mathrm{mod} /$ resource/view

Fecha de recepción: 20 de agosto, 2010

Fecha de aceptación: 28 de agosto, 2010 